\title{
PROFILING OF GENE EXPRESSION IN RAT LIVER AND RAT PRIMARY CULTURED HEPATOCYTES TREATED WITH PEROXISOME PROLIFERATORS
}

\author{
Kotaro TAMURA ${ }^{1}$, Atsushi ONO ${ }^{1}$, Toshikazu MIYAGISHIMA ${ }^{1}$, \\ Taku NAGAO ${ }^{2}$ and Tetsuro URUSHIDANI ${ }^{1,3}$ \\ ${ }^{1}$ Toxicogenomics Project, National Institute of Biomedical Innovation, \\ 7-6-8 Saito-Asagi, Ibaraki, Osaka 567-0085, Japan \\ ${ }^{2}$ National Institute of Health Sciences, \\ 1-18-1 Kamiyoga, Setagaya-Ku, Tokyo 158-8501, Japan \\ ${ }^{3}$ Department of Pathophysiology, Faculty of Pharmaceutical Sciences, \\ Doshisha Women's College of Liberal Arts, Kodo, Kyotanabe, Kyoto 610-0395, Japan
}

(Received August 18, 2006; Accepted September 11, 2006)

\begin{abstract}
The Toxicogenomics project has been constructing a large-scale database of about 150 compounds exposed to rat (single dose, 3, 6, 9, $24 \mathrm{hrs}$ and repeated dose for 3, 7, 1428 days with 3 dose levels) and rat hepatocytes $(2,8,24 \mathrm{hr}$ with 3 concentrations) and data of transcriptome in liver using GeneChip, and the related toxicological measures are being accumulated. In the present study, the data of three ligands of peroxisome proliferator activated receptor $\alpha$ (PPAR $\alpha)$, i.e., clofibrate, WY-14643 and gemfibrozil in our database were analyzed. Many of the $\beta$-oxidation-related genes were commonly induced in vivo and in vitro, whereas expression changes in genes related to cell proliferation, apoptosis, were detected in vivo (single and repeated dose) but not in vitro. Changes in those related to the immune response, coagulation and the stress response were also detectable exclusively in vivo. Using the genes mobilized in two or three PPAR $\alpha$ agonists, hierarchical clustering was performed on 32 compounds stored in our database. In the profiling of an in vivo single dose, benzbromarone and aspirin were located in the same cluster of the three PPAR $\alpha$ agonists. The clustering of in vitro data revealed that benzbromarone, three NSAIDs (aspirin, indomethacin and diclofenac sodium) and valproic acid belonged to the same cluster of PPAR $\alpha$ agonists, supporting the reports that benzbromarone,valproic acid and some NSAIDs were reported to be PPAR $\alpha$ agonists. Using the genes commonly up-regulated both in vivo and in vitro, principal component analysis was performed in 32 compounds, and principal component 1 was found to be the convenient parameter to extract PPAR $\alpha$ agonist-like compounds from the database.
\end{abstract}

KEY WORDS: Toxicogenomics, Hepatotoxicity, Peroxisome proliferator

\section{INTRODUCTION}

The Toxicogenomics Project is a 5-year collaborative project conducted by the National Institute of Health Sciences (NIHS) and 17 pharmaceutical companies in Japan which started in 2002 (Urushidani and Nagao, 2005). In April 2005, some rearrangements were made and now the project is conducted by NIHS, the National Institute of Biomedical Innovation, and 15 pharmaceutical companies. Its aim is to construct a large-scale toxicology database of transcriptome for prediction of toxicity of new chemical entities in the early stage of drug development. About 150 chemicals, mainly medicinal compounds, have been selected, and the following are examined for each. The in vivo test using rats consists of a single administration test (3, 6, 9 and $24 \mathrm{hr}$ with 4 dose levels including vehicle control) as well as a repeated administration test $(3,7,14$

Correspondence: Tetsuro URUSHIDANI (E-mail: turushid@ dwc.doshisha.ac.jp) 


\section{K. TAMURA et al.}

and 28 days with 4 dose levels including vehicle control) and the data of body weight, general symptoms, histopathological examination of liver and kidney, and blood biochemistry are obtained from each animal. The gene expression in liver (kidney in some cases) is comprehensively analyzed using Affymetrix GeneChip. An in vitro test using rat and human hepatocytes is also carried out to accomplish the bridging between the species. By the time the present study was performed, more than 100 chemicals covering wide medication categories had been finished or were ongoing, and the whole data set of 32 compounds had been stored in the database ready for analysis. We have started the analysis with three fibric acids in the database, i.e., clofibrate, WY-14643 and gemfibrozil (ligands of peroxisome proliferator-activated receptor $\alpha, \operatorname{PPAR} \alpha$ ). They have been extensively studied regarding their mechanism of toxicity, as we consider them excellent model cases for evaluating the quality of our database.

\section{MATERIALS AND METHODS}

\section{Compounds}

All compounds were of the highest grade obtainable from the suppliers listed in Table 1.

\section{In vivo studies}

Male Sprague-Dawley rats were purchased from Charles River Japan Inc., (Kanagawa, Japan) at 5weeks of age. After a 7-day quarantine and acclimatization period, the animals were divided into groups of 5 animals using a computerized stratified random grouping method based on body weight for each age. The animals were individually housed in stainless-steel cages on a $12 \mathrm{hr}$ light/dark cycle. Each animal was allowed free access to water and pellet food (CRF-1, sterilized by radiation, Oriental Yeast Co., Japan). The test compounds were suspended in $0.5 \%$ methylcellulose solution or corn oil. Animals were orally administered daily at three dose levels for 1, 3, 7, 14 and 28 days. The highest dose level for each was determined in a 1-week dose-finding study (data not shown), and $1 / 3$ and $1 / 10$ of that were set as middle and low doses, respectively. The dose levels are given in Table 1.

Blood samples were taken at 3, 6, 9, and $24 \mathrm{hr}$ after single dosing and $24 \mathrm{hr}$ after repeated dosing with a needle and a heparinized syringe from the abdominal artery of animals under ether anesthesia. Plasma biochemical assessments were conducted by using COBAS MIRA plus autoanalyzer (Roche Diagnostics,
Basel, SZ). After collecting the blood, the animals were euthanized by exsanguination from the abdominal veins and arteries under ether anesthesia. Livers were collected from each animal and weighed, then a portion (about $30 \mathrm{mg}$ ) of each left lateral lobe was put into RNAlater ${ }^{\circledR}$ (Ambion, Austin, TX, USA) for expression profiling. The remaining liver samples were fixed in $10 \%$ buffered formalin solution for routine histological processing. Paraffin sections were stained with hematoxylin and eosin for histopathological examination. The experimental protocols were reviewed and approved by the Ethics Review Committee for Animal Experimentation of the National Institute of Health Sciences.

\section{In vitro studies}

Hepatocytes were isolated from 6-week-old male Sprague-Dawley rats under sodium pentobarbital (120 $\mathrm{mg} / \mathrm{kg}$, ip) by a modified two-step collagenase perfusion method. The liver was perfused via the portal vein for $10 \mathrm{~min}$ with divalent cation-free EGTA $(0.5 \mathrm{mM})$ supplemented HEPES buffered Hank's balanced salt solution followed by a 10-min perfusion with HEPESbuffered normal Hank's balanced salt solution containing soybean trypsin inhibitor (Sigma, T-2011, $0.05 \mathrm{~g} /$ L) and collagenase (WAKO 034-10533, $0.5 \mathrm{~g} / \mathrm{L}$ ) at a flow rate of $10-30 \mathrm{ml} / \mathrm{min}$. Isolated cells were washed three times by $50 \mathrm{~g}$ for $1 \mathrm{~min}$ to obtain a parenchymal cell-enriched pellet. Hepatocytes were not used when their viability assessed by trypan blue exclusion was lower than $70 \%$. The cells were seeded into collagencoated six-well plates (BD BioCoat ${ }^{\circledR}$ Collagen I Cellware, BD Bioscience) at a density of $1 \times 10^{6}$ cells/well in $2 \mathrm{ml}$ HMC Bulletkit medium (CAMBREX) supplemented with $10 \%$ fetal bovine serum. Following an attachment period of $3 \mathrm{hr}$, the medium was replaced and kept overnight before drug exposure at $37^{\circ} \mathrm{C}$ in an atmosphere of $5 \% \mathrm{CO}_{2}$. The test compounds were added to the medium directly or as a $1,000 \times$ stock solution in dimethylsulfoxide. The highest concentration of each compound was determined in a pilot test based on cytotoxicity (ca. $20 \%$ release of lactate dehydrogenase) and 1/5 and 1/25 of that were set as middle and lowest concentrations (data not shown). After 2, 8 and 24 hr-exposure, the cells were dissolved with RLT buffer (Qiagen) and collected for expression profiling. GeneChip ${ }^{\circledR}$ analysis was performed in a duplicated manner for each time and concentration point.

\section{Expression profiling}

The livers were homogenized using Mill Mixer 
PPAR on rat liver gene expression in vivo and in vitro.

(Qiagen) and zirconium beads. Total RNA was isolated from the liver homogenate or the hepatocyte lysate using RNeasy kit. Purity of the RNA was checked by gel electrophoresis, and the OD260/280 nm ratio was between 2.0-2.2. Microarray analysis was conducted on 3 out of 5 samples for each group by using GeneChip ${ }^{\circledR}$ RAE230A probe arrays (Affymetrix, Santa Clara, CA, USA), containing 15923 probe sets. The

Table 1.

\begin{tabular}{|c|c|c|c|c|c|c|}
\hline \multirow{2}{*}{ Compound } & \multirow{2}{*}{ Abbreviation } & \multicolumn{2}{|l|}{ in vivo } & \multicolumn{2}{|l|}{ in vitro } & \multirow{2}{*}{ Supplier } \\
\hline & & Dose $(\mathrm{mg} / \mathrm{kg})$ & Vehicle & Concentration $(\mu \mathrm{M})$ & Vehicle & \\
\hline acetaminophen & APAP & $300,600,1000$ & $\mathrm{MC}$ & $300,1000,3000$ & Medium & Sigma \\
\hline allopurinol & APL & $15,50,150$ & $\mathrm{MC}$ & $5.6,28,140$ & DMSO & Sigma \\
\hline allyl alcohol & AA & $3,10,30$ & OIL & 4,20 & Medium & Tokyo kasei \\
\hline $\begin{array}{l}\text { alpha-naphthyl- } \\
\text { isothiocyanate }\end{array}$ & ANIT & $1.5,5,15$ & OIL & $8,40,200$ & DMSO & Kanto chemical \\
\hline aspirin & ASA & $45,150,450$ & $\mathrm{MC}$ & $120,600,3000$ & DMSO & Wako \\
\hline benzbromarone & $\mathrm{BBr}$ & $20,60,200$ & $\mathrm{MC}$ & $0.6,3,15$ & DMSO & Sigma \\
\hline bromobenzene & BBZ & $30,100,300$ & OIL & $8,40,200$ & DMSO & Tokyo kasei \\
\hline carbamazepine & CBZ & $30,100,300$ & $\mathrm{MC}$ & $12,60,300$ & DMSO & Sigma \\
\hline carbon tetrachloride & CCL4 & $10,30,100$ & OIL & $300,1000,3000$ & DMSO & Wako \\
\hline chlorpromazine & $\mathrm{CPZ}$ & $4.5,15,45$ & $\mathrm{MC}$ & $0.8,4,20$ & DMSO & Wako \\
\hline clofibrate & CFB & $30,100,300$ & OIL & $12,60,300$ & DMSO & Wako \\
\hline coumarin & CMA & $15,50,150$ & OIL & $12,60,300$ & DMSO & Tokyo kasei \\
\hline cyclophosphamide & $\mathrm{CPA}$ & $1.5,5,15$ & $\mathrm{MC}$ & $8,40,200$ & Medium & Ardrich \\
\hline diazepam & DZP & $25,75,250$ & $\mathrm{MC}$ & $5,25,125$ & DMSO & Wako \\
\hline diclofenac sodium & $\mathrm{DFNa}$ & $1,3,10$ & $\mathrm{MC}$ & $16,80,400$ & DMSO & Tokyo kasei \\
\hline ethionine & ET & $25,80,250$ & $\mathrm{MC}$ & $400,2000,10000$ & Medium & Tokyo kasei \\
\hline gemfibrozil & GFZ & $30,100,300$ & OIL & $4,20,100$ & DMSO & Sigma \\
\hline hexachlorobenzene & $\mathrm{HCB}$ & $30,100,300$ & OIL & $0.6,3,15$ & DMSO & Tokyo kasei \\
\hline indomethacin & $\mathrm{IM}$ & $0.5,1.6,5$ & $\mathrm{MC}$ & $12,60,300$ & DMSO & Sigma \\
\hline isoniazid & INAH & $10,50,100$ & $\mathrm{MC}$ & $400,2000,10000$ & Medium & Sigma \\
\hline $\begin{array}{l}\text { methapyrilene } \\
\text { hydrochloride }\end{array}$ & MP & $10,30,100$ & $\mathrm{MC}$ & $0.6,3,15$ & Medium & Sigma \\
\hline methotrexate & MTX & $\begin{array}{c}10,30,100 \text { (Single }) \\
0.1,0.3,1 \text { (Repeated })\end{array}$ & $\mathrm{MC}$ & $20,100,500$ & Medium & Wako \\
\hline nitrofurantoin & NFT & $10,30,100$ & $\mathrm{MC}$ & $5,25,125$ & DMSO & ICN \\
\hline omeprazole & $\mathrm{OPZ}$ & $100,300,1000$ & $\mathrm{MC}$ & $4.8,24,120$ & DMSO & Wako \\
\hline phenobarbital & $\mathrm{PB}$ & $10,30,100$ & $\mathrm{MC}$ & $300,1000,3000$ & Medium & Sigma \\
\hline phenylbutazone & $\mathrm{PhB}$ & $20,60,200$ & $\mathrm{MC}$ & $16,80,400$ & DMSO & Sigma \\
\hline phenytoin & PHE & $60,200,600$ & MC & $2.4,12,60$ & DMSO & Tokyo kasei \\
\hline propylthiouracil & PTU & $10,30,100$ & $\mathrm{MC}$ & $160,800,4000$ & Medium & Tokyo kasei \\
\hline rifampicin & RIF & $20,60,200$ & $\mathrm{MC}$ & $2.8,14,70$ & DMSO & Wako \\
\hline thioacetamide & TAA & $4.5,15,45$ & $\mathrm{MC}$ & $400,2000,10000$ & Medium & Ardrich \\
\hline valproate sodium & VPA & $45,150,450$ & $\mathrm{MC}$ & $400,2000,10000$ & Medium & Sigma \\
\hline Wy-14,643 & WY & $10,30,100$ & OIL & $8,40,200$ & DMSO & Tokyo kasei \\
\hline
\end{tabular}

Supplier information: Wako; Wako pure chemical industries, Osaka, Japan, Tokyo kasei; Tokyo kasei kogyo, Tokyo, Japan. ICN; ICN Biomedical Inc., Aurora, OH, USA, Sigma (St. Louis, MO, USA), Aldrich (St. Louis, MO, USA), Kanto chemical (Tokyo, Japan). 


\section{K. TAMURA et al.}

procedure was conducted basically according to the manufacturer's instructions using Superscript Choice System (Invitrogen, Carlsbad, CA, USA) and T7(dT)24-oligonucleotide primer (Affymetrix) for cDNA synthesis, cDNA Cleanup Module (Affymetrix) for purification, and BioArray High yield RNA Transcript Labeling Kit (Enzo Diagnostics, Farmingdale, NY, USA) for synthesis of biotin-labeled cRNA. Twenty $\mu \mathrm{g}$ of the fragmented cRNA was hybridized to a RAE230A probe array for $18 \mathrm{hr}$ at $45^{\circ} \mathrm{C}$ at $60 \mathrm{rpm}$, after which the array was washed and stained by streptavidin-phycoerythrin using Fluidics Station 400 (Affymetrix) and then scanned by Gene Array Scanner (Affymetrix). The data were analyzed by using GeneSpring ${ }^{\circledR}$ version 6.1 (Silicon Genetics, Santa Clara, CA, USA). Expression data were normalized using the mean value (global normalization). Filtering of the data was performed by flags (present or marginal call) in at least half of the samples, as well as the fold change, over the concurrent control value.

\section{Principal components analysis}

To test whether profiling on in vivo effects of compounds can be estimated from in vitro transcriptome data, principal component analysis (PCA) on the data of three time points $(24 \mathrm{hr}$ after in vivo single dose, 29 day after in vivo repeated dose, and $24 \mathrm{hr}$ after in vitro exposure) was independently conducted using the expression of 41 genes which changed to the same direction both in vitro and in vivo (single or repeated dose). The method of gene selection is described in the results section.

For calculation, we took the mean signals from three (in vivo) or two (in vitro) samples from each dose group and calculated the ratio for each respective control, and subsequently the values were transformed to $\log$ ratio to create a matrix. Each row corresponds to a different gene, and each column corresponds to a different condition including three different dose groups of 32 compounds. To compute the principal components, the eigenvalues and their corresponding eigenvectors were calculated from the correlation matrix of conditions. The calculations were done using the $\mathrm{R}$ version 2.2.0 (www.r-project.org) statistical environment.

\section{RESULTS}

\section{Pathology}

Toxicological changes observed in repeated administration of three peroxisome proliferators are summarized in Fig. 1. All three chemicals showed a significant increase in the relative liver to body weight after 4 days or later of administration (Fig. 1A). They also showed a significant decrease in triglyceride after the 4th day of administration, known to be directly related to their activity of PPAR $\alpha$ agonist (Fig. 1B). Signs of hepatotoxicity and an increase in ALT activity were observed in the 4th day of WY-14643- and the 29th day of gemfibrozil-treated groups (Fig. 1-C). In pathological examinations, granular degeneration of hepatocytes was noted in all compounds. Furthermore, an increase in hepatocyte proliferation was observed in WY-14643 and gemfibrozil. Treatment with WY14643 also induced necrosis of hepatocyte and hypertrophy of the bile duct (data not shown).

\section{Analysis of mRNA expression profile}

Differentially expressed genes in liver treated with clofibrate, WY-14643 and gemfibrozil were extracted as follows. For in vivo study, genes with present call in at least 3 out of 6 samples for each experimental set ( 3 each from control and treated group) were selected and used for further analysis. In the case of the in vitro study, genes with present call in at least 2 out of 4 samples in each experimental set ( 2 each from control and treated) were selected. Genes showing at least a 1.5 fold increase (or 1/1.5 fold decrease) both in middle and high dose vs. control at $\mathrm{p}<0.05$ by Student's $t$-test were extracted for each time point. In the case of in vitro study, the same procedure without use of $t$-test was employed. In the next step, the common genes selected in at least 2 out of three peroxisome proliferators for single, repeated, and in vitro experiments were extracted. The numbers of genes extracted as above were as follows: the up-regulated genes, 115/195/89 for in vivo-single/in vivo-repeated/ in vitro, respectively; and the down-regulated genes, $181 / 221 / 38$, for in vivo-single/in vivo-repeated/ in vitro, respectively. The overlapping of these genes is depicted in a Venn diagram in Fig. 2.

Comparing the extracted genes between the protocols, 71, 29, and 37 up-regulated genes were in common between the single and repeated administration, between single administration and in vitro, and between repeated administration and in vitro, respectively. For down-regulated genes, 44 genes were in common between single and repeated administration, whereas no common genes were present between in vivo and in vitro. These genes are listed in Table 2 (upregulated) and Table 3 (down-regulated).

Most of the genes categorized in $\beta$-oxidation and 
PPAR on rat liver gene expression in vivo and in vitro.

fatty acid and cholesterol synthesis, and the peroxisomal protein, were commonly changed both in vivo and in vitro. In general, genes related to lipid metabolism were commonly up-regulated in vivo and in vitro except that apolipoprotein A-IV, apolipoprotein M, and lipoprotein-binding protein were down-regulated only in vivo (mainly repeated dose). As for genes related to lipid metabolism other than that listed above, most of the up-regulated ones were common between in vivo and in vitro, whereas the down-regulated ones were only observed in vivo (single and repeated dose).

Of the genes related to carbohydrate metabolism, elevation of pyruvate dehydrogenase kinase 4 was observed both in vivo (single and repeated dose) and in vitro, whereas reduction of "pyruvate kinase liver and RBC" was observed only in vivo (mainly repeated dose) and others were increased in vivo (single and repeated dose).
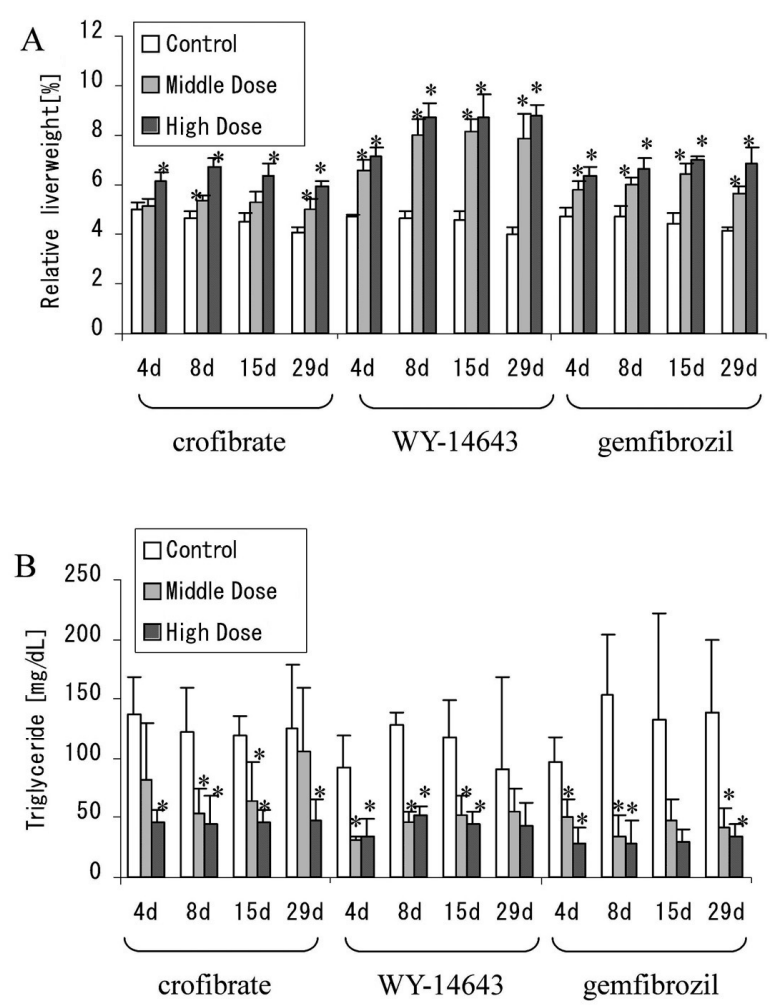

The genes classified as cell proliferation were upor down-regulated only in vivo (single and repeated dose). Some genes, including cyclin D1, showed more marked changes in single dose than in repeated dose. The changes of genes categorized in apoptosis were only detectable in vivo and their changes were also more prominent in single dose than in repeated dose.

Obvious changes were noted in the genes related to "drug and xenobiotic metabolism" and most of them occurred exclusively in vivo (single and repeated dose). The only observable changes in growth factor-related genes were a reduction of the in vivo repeated dose. Changes in the expression of genes related to "cellular morphogenesis" as well as the "stress response" were mainly noted in vivo (single and repeated dose). Many other genes categorized to "transcription activation and repression", "transporter", "cell adhesion", "immune response", "blood coagulation", "regulation of blood

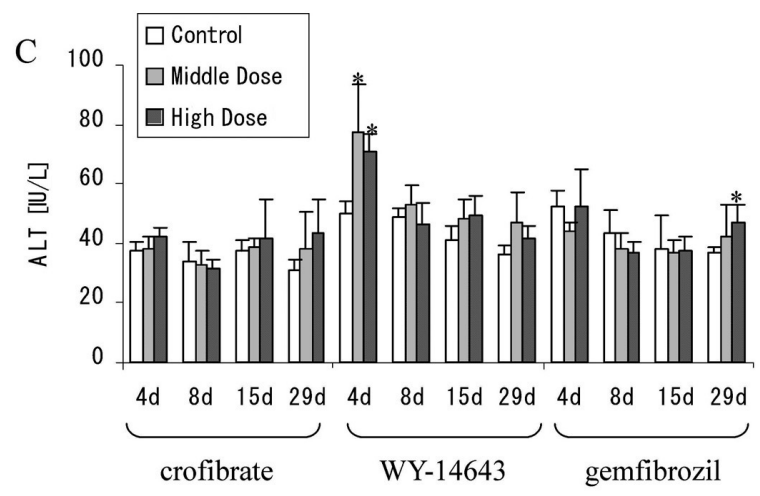

Fig. 1. Effects of clofibrate, WY-14643 and gemfibrozil on relative liver weight (A), plasma triglyceride (B) and plasma alanine amino transferase (ALT; C). Values were obtained $24 \mathrm{hr}$ after repeated administration of each drug for 3, 7, 14, and 28 days. Middle and high dose was 100 and $300 \mathrm{mg} / \mathrm{kg}$ for clofibrate, 30 and $100 \mathrm{mg} / \mathrm{kg}$ for WY-14643, and 100 and $300 \mathrm{mg} / \mathrm{kg}$ for gemfibrozil, respectively. For simplicity, data of the low dose was omitted. *Significantly different from control ( $p<0.05$, Student's $t$-test, $\mathrm{N}=5$ ). 
K. TAMURA et al.

pressure" were found to be down-regulated in vivo without any changes in vitro.

\section{Hierarchical cluster analysis}

Hierarchical clustering (complete linkage method, Euclidean distance) was performed in the 32 compounds stored in our database (the number at that stage of our analysis) using the data of gene expression in vivo or in vitro ( $24 \mathrm{hr}$ after middle and high dose). The probe sets used for analysis of in vivo data were 36 (up-regulated) and 35 (down-regulated) which showed a more than 1.5 fold change with $\mathrm{p}<0.05$ by Student's $t$-test both in middle and high dose of more than 2 compounds out of clofibrate, WY-14643 and gemfibrozil. The probe sets used for analysis of in vitro data were 49 (up-regulated) and 6 (down-regulated) which showed a more than 1.5 fold change with $\mathrm{p}<0.05$ by Student's $t$-test both in the middle and the high doses of more than 2 out of the three compounds. In clusters of single-dose experiments, benzbromarone and aspirin were classified into the same cluster of the three peroxisome proliferators (Fig. 3). In clusters of the in vitro experiments, benzbromarone, three non-steroidal antiinflammatory drugs (aspirin, indomethacin, and diclofenac sodium), valproic acid, and ANIT were classified into the same cluster of the three peroxisome proliferators (Fig. 4).

\section{PCA-based estimation of PPAR $\alpha$ activity}

As previously shown in Fig. 2, no common down-regulated genes existed between in vivo and in vitro, whereas 41 up-regulated genes were found to be common genes (between in vivo and in vitro) by PPAR $\alpha$ agonist treatment. We expected that these genes could be useful for prediction of in vivo effects from in vitro effects, so PCA analysis was conducted on the 32 compounds using these 41 genes.

A projection on the first two principal components for each condition, together with the contribution rate of the first three components, is shown in Fig. 5. It was obvious from the figure that the first principal component score (PC1) with high contribution (about $60 \%$ ) for all three experimental sets, was negatively correlated to the dose levels of these PPAR $\alpha$ ligands. Therefore, we reasoned that this negative PC1 score could be used to estimate the PPAR $\alpha$ activity in general.

Fig. 6 shows the plotting of negative PC1 values from the 32 compounds examined in vivo and in vitro. In this figure, a clearer comparison of putative PPAR $\alpha$ activity between the compounds can be performed. All the PPAR $\alpha$ agonists showed high scores both in vivo and in vitro. Benzbromarone, aspirin and valproic acid again showed high scores both in vivo and in vitro. It was also easy to pick up the compounds that showed high scores in vitro rather than in vivo, such as diclofenac and indomethacin.

\section{Decreased Genes}

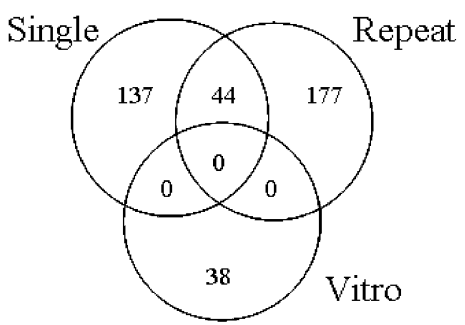

Fig. 2. Venn diagram of extracted genes. Differentially expressed genes in liver treated with clofibrate, WY-14643 and gemfibrozil were extracted as follows. For in vivo study (single and repeated) genes with present call in at least 3 out of 6 samples in each experimental set that show at least a 1.5fold increase (or 1/1.5-fold decrease) for both middle and high dose vs. control (at $\mathrm{p}<0.05$ by Student's $t$-test) were extracted for each time point. For the in vitro study, genes with present call at least 2 out of 4 samples in each experimental set showing the same criteria as in vivo (without using $t$-test) were extracted. The numbers in the diagram show the numbers of extracted genes in each category. 
PPAR on rat liver gene expression in vivo and in vitro.

Table 2. Up-regulated genes that are discussed in the text.

\begin{tabular}{|c|c|c|c|c|c|c|}
\hline & \multirow{2}{*}{ ProbeID } & \multirow{2}{*}{ GeneName } & \multirow{2}{*}{ Gene Symbol } & \multicolumn{2}{|c|}{ Vivo } & \multirow{2}{*}{ Vitro $^{c)}$} \\
\hline & & & & Single $\left.^{a}\right)$ & Repeated $^{\text {b) }}$ & \\
\hline \multicolumn{7}{|c|}{$\beta$-oxidation } \\
\hline \multirow[t]{2}{*}{$*$} & 1387783_a_at & acetyl-Coenzyme A acyltransferase 1 & Acaa1 & 3.9 & 5.8 & 8.4 \\
\hline & 1367735_at & acetyl-Coenzyme A dehydrogenase, long-chain & Acadl & 1.6 & 2.0 & 1.8 \\
\hline \multirow[t]{2}{*}{ * } & 1367897_at & $\begin{array}{l}\text { acyl-Coenzyme A dehydrogenase, very long } \\
\text { chain }\end{array}$ & Acadvl & 2.2 & 2.6 & 2.8 \\
\hline & 1367680_at & acyl-Coenzyme A oxidase 1, palmitoyl & Acox 1 & 2.7 & 3.1 & 4.3 \\
\hline * & 1367836_at & Carnitine palmitoyltransferase 1 liver & Cpt1a & 5.3 & 7.4 & 6.6 \\
\hline * & 1386946_at & carnitine palmitoyltransferase 1 , liver & Cpt1a & 4.3 & 4.6 & 8.5 \\
\hline * & 1386927_at & carnitine palmitoyltransferase 2 & Cpt2 & 5.5 & 6.2 & 3.0 \\
\hline * & 1367659_s_at & dodecenoyl-coenzyme A delta isomerase & Dci & 6.4 & 7.0 & 3.6 \\
\hline * & 1367777_at & 2,4-dienoyl CoA reductase 1, mitochondrial & Decr1 & 2.4 & 3.3 & 3.0 \\
\hline * & 1370818_at & $\begin{array}{l}\text { 2-4-dienoyl-Coenzyme A reductase } 2 \text { peroxi- } \\
\text { somal }\end{array}$ & Decr2 & 3.5 & 3.5 & 2.5 \\
\hline * & 1386885_at & enoyl coenzyme A hydratase 1, peroxisomal & Ech1 & 8.9 & 11.6 & 4.6 \\
\hline \multirow[t]{3}{*}{ * } & 1368283_at & $\begin{array}{l}\text { enoyl-Coenzyme A, hydratase/3-hydroxyacyl } \\
\text { Coenzyme A dehydrogenase }\end{array}$ & Ehhadh & 7.1 & 8.4 & 83.0 \\
\hline & 1370164_at & $\begin{array}{l}\text { Hydroxyacyl-Coenzyme A dehydrogenase al- } \\
\text { pha subunit }\end{array}$ & Hadha & 3.1 & 4.2 & 1.9 \\
\hline & 1367694_at & $\begin{array}{l}\text { hydroxyacyl-Coenzyme A dehydrogenase } \\
\text { beta subunit }\end{array}$ & Hadhb & 3.1 & 3.2 & 1.5 \\
\hline * & 1388210_at & Mitochondrial acyl-CoA thioesterase 1 & Mte1 & 24.1 & 32.1 & 3.9 \\
\hline \multirow[t]{3}{*}{ * } & 1388211_s_at & Mitochondrial acyl-CoA thioesterase 1 & Mte1 & 162.8 & 175.5 & 7.6 \\
\hline & \multicolumn{6}{|c|}{ Lipid mobilization } \\
\hline & 1370024_at & fatty acid binding protein 7 , brain & Fabp7 & 2.4 & 3.0 & 1.5 \\
\hline \multirow[t]{2}{*}{$*$} & 1368150_at & $\begin{array}{l}\text { solute carrier family } 27 \text { (fatty acid transporter), } \\
\text { member } 2\end{array}$ & Slc27a2 & 1.7 & 1.9 & 3.3 \\
\hline & 1398249_at & solute carrier family 25 member 20 & Slc $25 \mathrm{a} 20$ & 3.7 & 3.7 & 2.4 \\
\hline * & 1367950_at & solute carrier family 22 member 5 & Slc22a5 & 4.1 & 5.5 & 3.1 \\
\hline * & 1367689_a_at & Cd36 antigen & $\mathrm{Cd} 36$ & 5.8 & 16.4 & 3.7 \\
\hline * & 1386901_at & cd36 antigen & $\mathrm{Cd} 36$ & 5.2 & 9.6 & 3.8 \\
\hline * & 1375247_at & Monoglyceride lipase & Mgll & 3.2 & 7.4 & 3.3 \\
\hline * & 1370831_at & Monoglyceride lipase & Mgll & 4.2 & 7.4 & 3.5 \\
\hline \multirow[t]{5}{*}{ * } & 1388644_at & Monoglyceride lipase & Mgll & 7.2 & 9.4 & 3.9 \\
\hline & 1368317_at & aquaporin 7 & Aqp7 & 3.4 & 22.0 & 1.3 \\
\hline & \multicolumn{6}{|c|}{ Fatty acid and cholesterol synthesis } \\
\hline & 1367857_at & fatty acid desaturase 1 & Fads1 & 1.5 & 1.8 & 1.2 \\
\hline & 1368453_at & fatty acid desaturase 2 & Fads2 & 2.4 & 3.8 & 1.3 \\
\hline \multirow[t]{2}{*}{$*$} & 1370355_at & Stearoyl-Coenzyme A desaturase 1 & Scd1 & 1.6 & 2.6 & 2.2 \\
\hline & 1372318_at & $\begin{array}{l}\text { ELOVL family member } 6 \text { elongation of long } \\
\text { chain fatty acids yeast }\end{array}$ & rELO2 & 4.6 & 7.2 & 1.5 \\
\hline \multirow[t]{2}{*}{$*$} & 1388108_at & $\begin{array}{l}\text { ELOVL family member } 6 \text { elongation of long } \\
\text { chain fatty acids yeast }\end{array}$ & rELO2 & 5.4 & 9.6 & 2.1 \\
\hline & 1367767_at & 3-hydroxy-3-methylglutaryl CoA lyase & Hmgcl & 1.9 & 3.4 & 1.5 \\
\hline * & 1370310_at & $\begin{array}{l}\text { 3-hydroxy-3-methylglutaryl-Coenzyme A syn- } \\
\text { thase } 2\end{array}$ & Hmgcs2 & 1.9 & 1.9 & 11.5 \\
\hline & \multicolumn{6}{|c|}{ Ohter lipid methabolism related } \\
\hline \multirow[t]{2}{*}{ * } & 1386880_at & acetyl-Coenzyme A acyltransferase 2 & Acaa2 & 2.0 & 2.5 & 4.3 \\
\hline & 1373778_at & Acetyl-Coenzyme A carboxylase beta & Acacb & 2.0 & 3.6 & 1.4 \\
\hline
\end{tabular}


K. TAMURA et al.

Table 2. Continued.

\begin{tabular}{|c|c|c|c|c|c|c|}
\hline \multirow{2}{*}{\multicolumn{2}{|c|}{ ProbeID }} & \multirow{2}{*}{ GeneName } & \multirow{2}{*}{ Gene Symbol } & \multicolumn{2}{|c|}{ Vivo } & \multirow{2}{*}{ Vitro $^{\mathrm{c}}$} \\
\hline & & & & Singlea) & Repeated $^{\text {b) }}$ & \\
\hline & 1367763_at & Acetyl-coenzyme A acetyltransferase 1 & Acat1 & 2.2 & 3.4 & 2.1 \\
\hline & 1368177_at & acyl-CoA synthetase long-chain family member 3 & Acsl3 & 2.4 & 5.8 & 3.6 \\
\hline \multirow{3}{*}{$*$} & 1371886_at & Carnitine acetyltransferase & Crat & 9.7 & 17.4 & 2.5 \\
\hline & 1368426_at & carnitine $O$-octanoyltransferase & Crot & 2.8 & 3.1 & 2.0 \\
\hline & 1387183_at & Carnitine $O$-octanoyltransferase & Crot & 6.4 & 6.4 & 3.6 \\
\hline \multirow{3}{*}{$*$} & 1398250_at & cytosolic acyl-CoA thioesterase 1 & Cte 1 & 537.8 & 971.5 & 1906.3 \\
\hline & 1368206_at & peroxisomal acyl-CoA thioesterase 1 & Pte1 & 3.6 & 5.8 & 1.5 \\
\hline & 1369485_at & cytoplasmic acetyl-CoA hydrolase & $\mathrm{rACH}$ & 2.3 & 2.9 & 2.7 \\
\hline \multirow[t]{2}{*}{$*$} & 1388924_at & Angiopoietin-like protein 4 & Angptl4 & 5.3 & 5.6 & 5.5 \\
\hline & \multicolumn{6}{|c|}{ Peroxisomal Protein } \\
\hline$*$ & 1379361_at & Peroxisomal biogenesis factor $11 \mathrm{~A}$ & Pex11a & 16.5 & 12.1 & 4.9 \\
\hline$*$ & 1387740_at & peroxisomal biogenesis factor $11 \mathrm{~A}$ & Pex11a & 14.8 & 13.3 & 7.4 \\
\hline \multicolumn{7}{|c|}{ Carbohydrate methabolism } \\
\hline$*$ & 1369150_at & pyruvate dehydrogenase kinase, isoenzyme 4 & Pdk4 & 9.7 & 17.9 & 15.9 \\
\hline & 1370509_at & $\begin{array}{l}\text { Pyruvate dehydrogenase phosphatase isoen- } \\
\text { zyme } 2\end{array}$ & Pdp2 & 2.3 & 1.9 & 1.3 \\
\hline & 1369560_at & glycerol-3-phosphate dehydrogenase 1 (soluble) & Gpd1 & 3.3 & 3.6 & 2.8 \\
\hline & 1371363_at & Glycerol-3-phosphate dehydrogenase 1 soluble & Gpd1 & 2.4 & 2.3 & 2.2 \\
\hline & 1387670_at & Glycerol-3-phosphate dehydrogenase 2 & Gpd2 & 6.2 & 7.5 & 1.5 \\
\hline & 1370870_at & Malic enzyme 1 & Me1 & 5.0 & 15.0 & 1.2 \\
\hline & 1370067_at & malic enzyme 1 & $\mathrm{Me} 1$ & 5.1 & 12.0 & 1.1 \\
\hline \multicolumn{7}{|c|}{ Proliferation } \\
\hline & $\overline{1371150 \_ \text {at }}$ & Cyclin D1 & Ccnd1 & 2.2 & 1.7 & 1.1 \\
\hline & 1383075_at & Cyclin D1 & Ccnd1 & 3.7 & 1.6 & 1.1 \\
\hline & 1368947_at & $\begin{array}{l}\text { growth arrest and DNA-damage-inducible } 45 \\
\text { alpha }\end{array}$ & Gadd45a & 3.6 & 4.0 & 1.3 \\
\hline & 1368308_at & $\begin{array}{l}\text { myelocytomatosis viral oncogene homolog } \\
\text { (avian) }\end{array}$ & Myc & 2.2 & 5.7 & 1.2 \\
\hline & 1373473_a_at & Nucleosome assembly protein 1 -like 1 & Nap111 & 3.3 & 3.9 & 1.2 \\
\hline & 1370826_at & Nucleosome assembly protein 1 -like 1 & Nap111 & 2.0 & 2.2 & 1.1 \\
\hline & 1387977_at & Nibrin & Nbn & 3.3 & 2.3 & 1.3 \\
\hline & 1387062_a_at & checkpoint kinase 1 homolog (S. pombe) & Chek1 & 2.8 & 2.7 & 1.3 \\
\hline & 1371352_at & High mobility group protein 17 & Hmgn2 & 1.8 & 1.9 & 1.5 \\
\hline & 1370334_at & Evectin-1 & Plekhb1 & 3.4 & 2.2 & 1.4 \\
\hline & 1370413_at & Pregnancy specific beta-1-glycoprotein 4 & Psg4 & 1.8 & 1.7 & 1.2 \\
\hline & 1389403_at & Bone morphogenetic protein 7 & Bmp7 & 1.7 & 1.9 & 1.2 \\
\hline & 1368143_at & Annexin A7 & Anxa7 & 2.3 & 3.5 & 1.0 \\
\hline \multicolumn{7}{|c|}{ Growth factor } \\
\hline & 1369608_at & fibroblast growth factor 16 & Fgf16 & 1.8 & 1.8 & 1.2 \\
\hline \multicolumn{7}{|c|}{ Apoptosis } \\
\hline & 1368888_a_at & Reticulon 4 & Rtn4 & 2.5 & 8.9 & 1.1 \\
\hline & 1388027_a_at & Reticulon 4 & Rtn4 & 3.5 & 13.3 & 1.1 \\
\hline & 1387521_at & programmed cell death 4 & Pdcd 4 & 1.3 & 2.3 & 1.2 \\
\hline \multicolumn{7}{|c|}{$\underline{\text { Cellular morphogenesis }}$} \\
\hline$*$ & 1368475_at & $\begin{array}{l}\text { collagen-like tail subunit of asymmetric acetyl- } \\
\text { cholinesterase }\end{array}$ & Colq & 7.8 & 7.7 & 2.4 \\
\hline
\end{tabular}


PPAR on rat liver gene expression in vivo and in vitro.

Table 2. Continued.

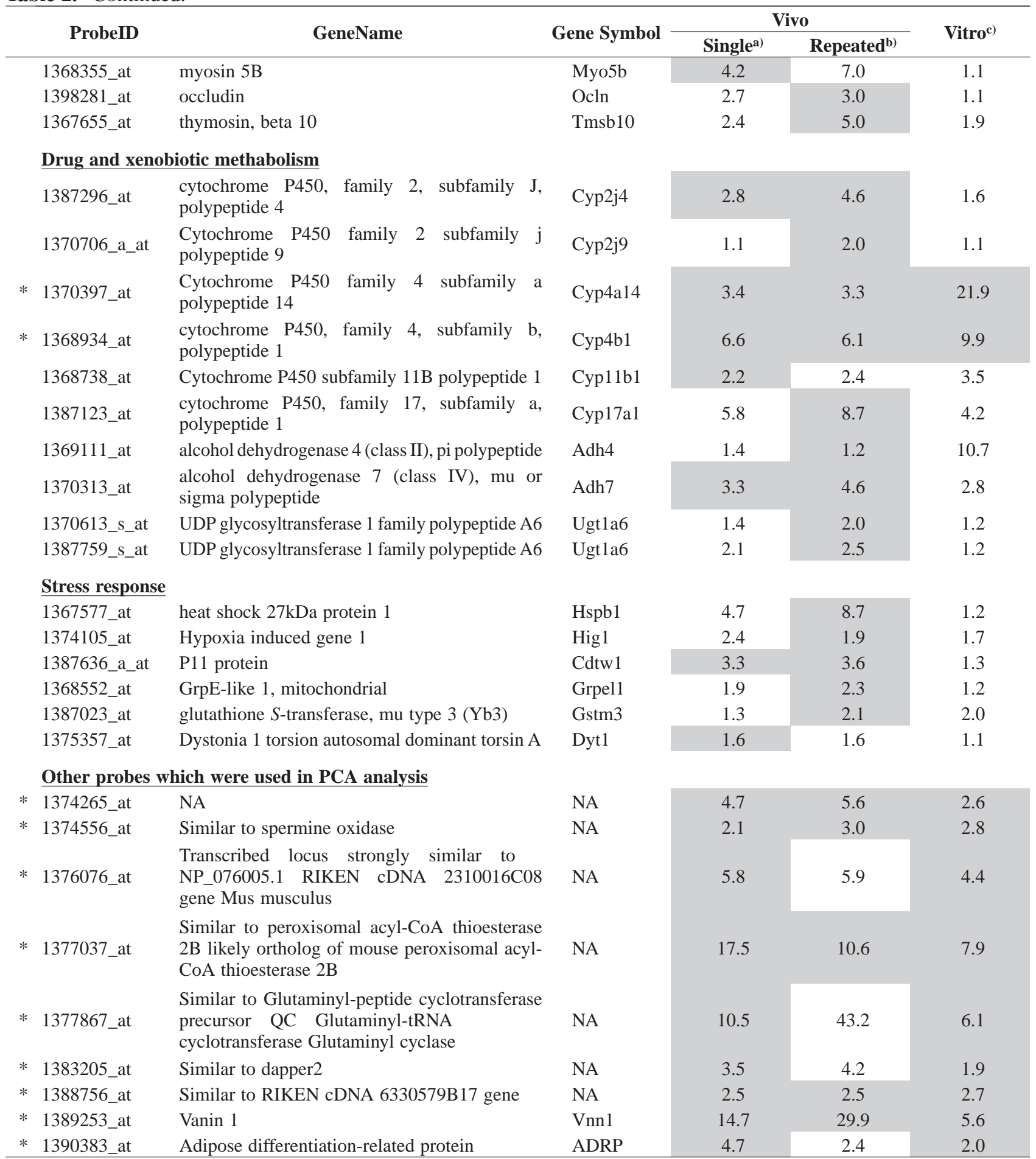

a): The largest fold change among the single dose studies of CFB, WY and GFZ is shown. ${ }^{\text {b): }}$ The largest fold change among the repeated dose studies of CFB, WY and GFZ is shown. ${ }^{c)}$ : The largest fold change among in vitro studies of CFB, WY and GFZ is shown. The columns are shaded when the corresponding probe sets appear in Fig. 2. *: Probes which were used in the PCA analysis. 
K. TAMURA et al.

Table 3. Down-regulated genes that are discussed in the text.

\begin{tabular}{|c|c|c|c|c|c|}
\hline \multirow{2}{*}{ Probe ID } & \multirow{2}{*}{ Gene Name } & \multirow{2}{*}{ Gene Symbol - } & \multicolumn{2}{|c|}{ Vivo } & \multirow{2}{*}{ Vitro $^{\text {c) }}$} \\
\hline & & & Single $^{\text {a) }}$ & Repeated $^{\mathbf{b}}$ & \\
\hline \multicolumn{5}{|c|}{ Lipid mobilization } & \\
\hline 1368520_at & apolipoprotein A-IV & Apoa4 & -4.0 & -255.0 & -1.2 \\
\hline 1386980_at & apolipoprotein $\mathrm{M}$ & Apom & -1.4 & -5.3 & -1.1 \\
\hline 1398859_at & Lipoprotein-binding protein & Hdlbp & -1.8 & -1.9 & -1.1 \\
\hline \multicolumn{5}{|c|}{ Other lipid Methabolism related } & \\
\hline 1387959_at & Lysophospholipase & LOC246266 & -2.2 & -3.4 & -2.3 \\
\hline 1370530_a_at & Phospholipase D1 & Pld1 & -2.0 & -1.8 & -1.4 \\
\hline 1369526_at & $\begin{array}{l}\text { acyl-Coenzyme A dehydrogenase, short/branched } \\
\text { chain }\end{array}$ & Acadsb & -2.0 & -2.9 & -1.8 \\
\hline \multicolumn{5}{|c|}{ Carbohydrate methabolism } & \\
\hline 1368651_at & Pyruvate kinase liver and RBC & Pklr & -6.1 & -5.8 & -1.4 \\
\hline 1387263_at & pyruvate kinase, liver and $\mathrm{RBC}$ & Pklr & -11.1 & -15.7 & -3.1 \\
\hline \multicolumn{6}{|l|}{ Proliferation } \\
\hline 1387129_at & $\begin{array}{l}\text { X-ray repair complementing defective repair in } \\
\text { Chinese hamster cells } 1\end{array}$ & Xrcc1 & -1.9 & -1.4 & -1.2 \\
\hline 1372863_at & MYC binding protein 2 & Mycbp2 & -2.3 & -3.0 & -1.2 \\
\hline 1373291_at & Deleted in liver cancer 1 & Dlc1 & -2.0 & -2.7 & -1.3 \\
\hline 1373332_at & Casein kinase 1 delta & Csnk1d & -1.9 & -1.7 & -1.1 \\
\hline 1398273_at & ephrin A1 & Efna1 & -2.1 & -1.6 & -1.3 \\
\hline \multicolumn{6}{|c|}{ Transcription activation and repression } \\
\hline 1371202_a_at & Nuclear factor I B & Nfib & -2.6 & -3.2 & -1.3 \\
\hline 1388167_at & Nuclear factor I B & Nfib & -2.5 & -2.8 & -1.4 \\
\hline 1370946_at & Nuclear factor I X & Nfix & -2.5 & -4.1 & -1.3 \\
\hline 1368221_at & nuclear receptor subfamily 3 , group $\mathrm{C}$, member 1 & $\mathrm{Nr} 3 \mathrm{c} 1$ & -2.3 & -2.5 & -1.3 \\
\hline 1369244_at & aryl hydrocarbon receptor nuclear translocator & Arnt & -1.8 & -2.2 & -1.3 \\
\hline 1372601_at & Activating transcription factor 5 & Atf5 & -1.9 & -2.8 & -1.1 \\
\hline 1367601_at & $\begin{array}{l}\mathrm{Cbp} / \mathrm{p} 300 \text {-interacting transactivator, with Glu/Asp- } \\
\text { rich carboxy-terminal domain, } 2\end{array}$ & Cited2 & -3.1 & -2.2 & -1.3 \\
\hline 1367602_at & $\begin{array}{l}\text { Cbp p300-interacting transactivator with Glu Asp- } \\
\text { rich carboxy-terminal domain } 2\end{array}$ & Cited 2 & -3.0 & -2.3 & -1.1 \\
\hline 1387165_at & $\begin{array}{l}\text { v-maf musculoaponeurotic fibrosarcoma (avian) } \\
\text { oncogene homolog (c-maf) }\end{array}$ & Maf & -2.0 & -3.7 & -1.9 \\
\hline 1371781_at & Signal transducer and activator of transcription 3 & Stat3 & -2.2 & -2.6 & -1.1 \\
\hline \multicolumn{6}{|l|}{ Growth factor } \\
\hline 1370830_at & Epidermal growth factor receptor & Egfr & -5.9 & -3.8 & -1.3 \\
\hline 1373829_at & Fibroblast growth factor receptor 2 & Fgfr2 & -1.6 & -2.5 & -1.3 \\
\hline 1370941_at & $\begin{array}{l}\text { Platelet derived growth factor receptor alpha } \\
\text { polypeptide }\end{array}$ & Pdgfra & -1.5 & -2.7 & -1.3 \\
\hline 1367652_at & insulin-like growth factor binding protein 3 & Igfbp3 & -1.6 & -2.6 & -1.3 \\
\hline \multicolumn{6}{|l|}{ Apoptosis } \\
\hline 1369941_at & death-associated protein & Dap & -2.0 & -2.8 & -1.1 \\
\hline 1369902_at & $\mathrm{Bcl} 2$ modifying factor & $\mathrm{Bmf}$ & -12.3 & -22.2 & -3.4 \\
\hline 1370512_at & $\begin{array}{l}\text { Androgen receptor-related apoptosis-associated } \\
\text { protein CBL27 }\end{array}$ & Cbl27 & -2.9 & -3.1 & -1.3 \\
\hline 1371491_at & Notch gene homolog 1 Drosophila & Notch1 & -1.9 & -1.9 & -1.4 \\
\hline
\end{tabular}


PPAR on rat liver gene expression in vivo and in vitro.

Table 3. Continued.

\begin{tabular}{|c|c|c|c|c|c|}
\hline \multirow{2}{*}{ Probe ID } & \multirow{2}{*}{ Gene Name } & \multirow{2}{*}{ Gene Symbol } & \multicolumn{2}{|c|}{ Vivo } & \multirow{2}{*}{ Vitro $^{c)}$} \\
\hline & & & Single ${ }^{a)}$ & Repeated $^{\text {b) }}$ & \\
\hline 1398362_at & Notch gene homolog 2 Drosophila & Notch2 & -3.5 & -5.5 & -1.2 \\
\hline 1370243_a_at & Prothymosin alpha & Ptma & -1.5 & -2.5 & -1.0 \\
\hline \multicolumn{6}{|l|}{ Cell adhesion } \\
\hline 1386947_at & cadherin 1 & Cdh1 & -2.9 & -2.1 & -1.2 \\
\hline 1369224_at & cadherin 17 & $\operatorname{Cdh} 17$ & -4.5 & -10.1 & -1.5 \\
\hline 1368642_at & cadherin 2 & $\mathrm{Cdh} 2$ & -2.2 & -3.3 & -1.2 \\
\hline 1387259_at & Cadherin 2 & $\operatorname{Cdh} 2$ & -2.2 & -2.3 & -1.1 \\
\hline 1369854_a_at & CEA-related cell adhesion molecule 1 & Ceacam1 & -2.0 & -2.8 & -1.4 \\
\hline 1370371_a_at & CEA-related cell adhesion molecule 10 & Ceacam 10 & -1.7 & -2.2 & -1.2 \\
\hline 1370234_at & Fibronectin 1 & Fn1 & -2.7 & -3.0 & -1.1 \\
\hline 1382027_at & Integrin beta $3 \mathrm{Cd} 61$ & Itgb3 & -2.3 & -3.5 & -1.7 \\
\hline 1372002_at & Gap junction membrane channel protein alpha 1 & Gja1 & -1.5 & -2.2 & -1.1 \\
\hline 1367849_at & syndecan 1 & Sdc1 & -1.6 & -2.1 & -1.1 \\
\hline 1370043_at & activated leukocyte cell adhesion molecule & Alcam & -2.4 & -3.4 & -1.3 \\
\hline 1374432_at & Activated leukocyte cell adhesion molecule & Alcam & -2.1 & -5.0 & -1.6 \\
\hline 1370108_a_at & Lin-7 homolog a C. elegans & Veli1 & -2.5 & -3.9 & -3.7 \\
\hline 1373027_at & Afadin & Af6 & -1.9 & -2.3 & -1.2 \\
\hline \multicolumn{6}{|c|}{ Cellular morphogenesis } \\
\hline 1388459_at & Collagen type XVIII alpha 1 & Col18a1 & -3.0 & -3.6 & -1.2 \\
\hline 1370959_at & Collagen type III alpha 1 & Col3a1 & -1.9 & -2.6 & -1.6 \\
\hline 1376099_at & Collagen type V alpha 1 & Col5a1 & -2.2 & -3.2 & -1.4 \\
\hline 1370895_at & Collagen type V alpha 2 & Col5a2 & -1.5 & -2.1 & -1.2 \\
\hline 1371725_at & Myosin heavy polypeptide 9 & Myh9 & -2.7 & -2.9 & -1.2 \\
\hline 1387402_at & myosin, heavy polypeptide 9 & Myh9 & -2.4 & -3.3 & -1.1 \\
\hline 1369720_at & myosin $\mathrm{Ib}$ & Myolb & -2.1 & -2.9 & -1.1 \\
\hline 1386941_at & plectin & Plec1 & -2.6 & -2.7 & -1.2 \\
\hline 1370993_at & Laminin gamma 1 & Lamc1 & -2.2 & -2.7 & -1.2 \\
\hline 1386956_at & scavenger receptor class B, member 1 & Scarb1 & -1.4 & -3.3 & -1.2 \\
\hline \multicolumn{6}{|c|}{ Immune response } \\
\hline 1371926_at & Interleukin 6 signal transducer & Il6st & -2.2 & -1.9 & -1.1 \\
\hline 1368280_at & cathepsin $\mathrm{C}$ & Ctsc & -2.1 & -3.2 & -1.3 \\
\hline 1387005_at & cathepsin $\mathrm{S}$ & Ctss & -1.3 & -2.4 & -1.1 \\
\hline 1387893_at & Complement component $1 \mathrm{~s}$ subcomponent & $\mathrm{C} 1 \mathrm{~s}$ & -2.3 & -13.6 & -1.3 \\
\hline 1370892_at & Complement component $4 \mathrm{a}$ & $\mathrm{C} 4 \mathrm{a}$ & -2.3 & -3.6 & -1.1 \\
\hline 1368558_s_at & allograft inflammatory factor 1 & Aif1 & -1.7 & -3.3 & -1.7 \\
\hline 1370479_x_at & Alpha-2u globulin PGCL4 & Obp3 & -2.9 & -81.0 & -1.2 \\
\hline 1387985_a_at & Alpha-2u globulin PGCL4 & Obp3 & -2.6 & -207.5 & -1.1 \\
\hline \multicolumn{6}{|l|}{ Coagulation } \\
\hline 1374320_at & Coagulation factor 5 & F5 & -2.5 & -3.8 & -1.6 \\
\hline 1387351_at & fibrillin-1 & Fbn 1 & -1.9 & -3.2 & -1.4 \\
\hline 1371258_at & Fibrinogen alpha polypeptide & Fga & -2.1 & -1.8 & -1.5 \\
\hline 1387323_at & kallikrein B, plasma 1 & Klk3 & -2.6 & -2.7 & -2.4 \\
\hline 1369225_at & kininogen 1 & Kng1 & -1.8 & -2.5 & -1.1 \\
\hline
\end{tabular}


Table 3. Continued.

\begin{tabular}{|c|c|c|c|c|c|}
\hline \multirow{2}{*}{ Probe ID } & \multirow{2}{*}{ Gene Name } & \multirow{2}{*}{ Gene Symbol } & \multicolumn{2}{|c|}{ Vivo } & \multirow{2}{*}{ Vitro ${ }^{\mathrm{c}}$} \\
\hline & & & Single $^{a)}$ & Repeated $^{\text {b) }}$ & \\
\hline \multicolumn{6}{|c|}{ Drug and xenobiotic methabolism } \\
\hline 1387243_at & $\begin{array}{l}\text { Cytochrome P450 family } 1 \text { subfamily a polypep- } \\
\text { tide } 2\end{array}$ & Cyp1a2 & -2.2 & -8.1 & -1.2 \\
\hline 1387913_at & $\begin{array}{l}\text { Cytochrome P450 family } 2 \text { subfamily d polypep- } \\
\text { tide } 22\end{array}$ & Cyp2d22 & -2.6 & -4.0 & -1.6 \\
\hline 1368608_at & $\begin{array}{l}\text { cytochrome P450, family } 2 \text {, subfamily f, polypep- } \\
\text { tide } 2\end{array}$ & Сyp2f2 & -2.0 & -3.0 & -1.3 \\
\hline 1368265_at & cytochrome P450 monooxygenase CYP2T1 & Cyp2t1 & -2.2 & -3.7 & -1.3 \\
\hline 1370387_at & $\begin{array}{l}\text { Cytochrome P450 family } 3 \text { subfamily a polypep- } \\
\text { tide } 13\end{array}$ & Cyp3a13 & -3.6 & -50.2 & -1.7 \\
\hline 1368467_at & $\begin{array}{l}\text { cytochrome P450, family } 4 \text {, subfamily F, polypep- } \\
\text { tide } 2\end{array}$ & Cyp4f2 & -1.7 & -2.3 & -1.4 \\
\hline 1367979_s_at & cytochrome P450, subfamily 51 & Cyp51 & -2.1 & -1.4 & -1.0 \\
\hline 1389218_at & UDP-glucose ceramide glucosyltransferase-like 1 & Ugcgl1 & -2.9 & -2.1 & -1.3 \\
\hline 1367938_at & UDP-glucose dehydrogenase & Ugdh & -2.4 & -1.9 & -1.2 \\
\hline 1388410_at & UDP-glucose pyrophosphorylase 2 & Ugp2 & -3.0 & -4.4 & -1.2 \\
\hline \multicolumn{6}{|l|}{ Transport } \\
\hline 1370465_at & $\begin{array}{l}\text { ATP-binding cassette sub-family B MDR TAP } \\
\text { member } 4\end{array}$ & Abcb1 & -5.5 & -10.8 & -1.3 \\
\hline 1368497_at & $\begin{array}{l}\text { ATP-binding cassette, sub-family C (CFTR/MRP), } \\
\text { member } 2\end{array}$ & Abcc2 & -4.4 & -2.5 & -1.4 \\
\hline 1369455_at & $\begin{array}{l}\text { ATP-binding cassette, sub-family G (WHITE), } \\
\text { member } 5\end{array}$ & Abcg5 & -1.6 & -3.1 & -1.9 \\
\hline 1369440_at & $\begin{array}{l}\text { ATP-binding cassette, sub-family G (WHITE), } \\
\text { member } 8\end{array}$ & $\operatorname{Abcg} 8$ & -2.4 & -5.6 & -3.9 \\
\hline 1398862_at & $\begin{array}{l}\text { ATPase Ca transporting cardiac muscle slow } \\
\text { twitch } 2\end{array}$ & Atp2a2 & -2.6 & -3.9 & -1.2 \\
\hline 1368698_at & ATPase Ca transporting plasma membrane 2 & Atp2b2 & -2.3 & -3.4 & -1.9 \\
\hline 1387285_at & ATPase, $\mathrm{Ca}++$ transporting, plasma membrane 2 & Atp2b2 & -2.1 & -2.1 & -1.7 \\
\hline 1368621_at & aquaporin 9 & Aqp9 & -1.9 & -8.4 & -1.4 \\
\hline 1390591_at & $\mathrm{Na} P \mathrm{Pi}$ cotransporter 4 & Slc17a3 & -1.8 & -4.9 & -1.5 \\
\hline 1369746_a_at & Solute carrier family 21 member 10 & Slc21a10 & -1.8 & -3.5 & -1.6 \\
\hline 1368461_at & $\begin{array}{l}\text { solute carrier family } 22 \text { (organic anion trans- } \\
\text { porter), member } 8\end{array}$ & Slc22a 8 & -2.0 & -3.1 & -1.2 \\
\hline 1369169_at & $\begin{array}{l}\text { solute carrier family } 23 \text { (nucleobase transporters), } \\
\text { member } 1\end{array}$ & Slc23a1 & -1.9 & -2.6 & -1.3 \\
\hline 1368600_at & $\begin{array}{l}\text { solute carrier family } 26 \text { (sulfate transporter), mem- } \\
\text { ber } 1\end{array}$ & Slc26a1 & -2.0 & -2.5 & -1.3 \\
\hline 1369099_at & $\begin{array}{l}\text { solute carrier family } 30 \text { (zinc transporter), member } \\
1\end{array}$ & Slc30a1 & -1.6 & -4.4 & -1.3 \\
\hline 1386960_at & $\begin{array}{l}\text { solute carrier family } 37 \text { (glycerol-6-phosphate } \\
\text { transporter), member } 4\end{array}$ & Slc37a4 & -2.2 & -2.3 & -1.2 \\
\hline 1368296_at & $\begin{array}{l}\text { Solute carrier organic anion transporter family } \\
\text { member } 2 \mathrm{~b} 1\end{array}$ & Slco2b1 & -2.1 & -2.4 & -1.3 \\
\hline \multicolumn{6}{|c|}{ Stress response } \\
\hline 1371442_at & Hypoxia up-regulated 1 & Hyou1 & -2.9 & -3.9 & -1.6 \\
\hline 1370665_at & Hypoxia up-regulated 1 & Hyou1 & -2.2 & -3.3 & -1.2 \\
\hline
\end{tabular}


PPAR on rat liver gene expression in vivo and in vitro.

Table 3. Continued.

\begin{tabular}{|c|c|c|c|c|c|}
\hline \multirow{2}{*}{ Probe ID } & \multirow{2}{*}{ Gene Name } & \multirow{2}{*}{ Gene Symbol } & \multicolumn{2}{|c|}{ Vivo } & \multirow{2}{*}{ Vitro $^{\mathrm{c})}$} \\
\hline & & & Single ${ }^{a}$ & Repeated $^{\text {b) }}$ & \\
\hline \multicolumn{5}{|c|}{ Regulation of blood pressure } & \\
\hline 1387811_at & angiotensinogen & Agt & -2.2 & -2.1 & -1.1 \\
\hline 1369664_at & arginine vasopressin receptor $1 \mathrm{~A}$ & Avpr1a & -3.0 & -2.7 & -1.4 \\
\hline 1367801_at & endothelin converting enzyme 1 & Ece1 & -1.9 & -2.2 & -1.2 \\
\hline 1386953_at & hydroxysteroid 11-beta dehydrogenase 1 & Hsd11b1 & -2.2 & -4.6 & -1.1 \\
\hline 1368102_at & hydroxysteroid 11-beta dehydrogenase 2 & Hsd11b2 & -1.8 & -3.6 & -1.9 \\
\hline 1387994_at & Hydroxysteroid 17-beta dehydrogenase 9 & Hsd17b9 & -1.6 & -1.8 & -1.3 \\
\hline \multicolumn{5}{|l|}{$\underline{\text { Others }}$} & \\
\hline 1368490_at & CD14 antigen & $\mathrm{Cd} 14$ & -2.1 & -5.1 & -1.3 \\
\hline 1370891_at & CD48 antigen & $\mathrm{Cd} 48$ & -1.3 & -2.1 & -1.2 \\
\hline 1367709_at & CD63 antigen & Cd63 & -1.4 & -2.9 & -1.1 \\
\hline
\end{tabular}

a): The smallest ratio to control value observed in single-dose studies of CFB, WY and GFZ is shown. Negative figure means the reciprocal number of ratio; e.g., -3.0 means that one of the drugs reduced the gene expression to $1 / 3$ of corresponding control. ${ }^{\text {b): }}$ The smallest ratio to control value observed in repeated dose studies of CFB, WY and GFZ is shown. c): The smallest ratio to control value observed in vitro studies of CFB, WY and GFZ is shown. The columns are shaded when the corresponding probe sets appear in Fig. 2.

\section{DISCUSSION}

In the present study, analysis of gene expression in rat liver was done with three peroxisome proliferators, clofibrate, WY-14643 and gemfibrozil, stored in our database. The changes of gene expression by these compounds observed in vivo (single and repeated) were largely in accordance with the report by Kramer et al. (2003), in which the effect of clofibrate on the gene expression profile in rat liver was analyzed. Among the genes whose expression was affected, a large number of genes were overlapped between in vivo and in vitro, both in up- and down-regulated ones. Between in vivo and in vitro experiments, however, there were many common genes in up-regulated ones but none in down-regulated ones.

A large number of genes related to b-oxidation were up-regulated by a single dose, and similar changes were also noted for in vitro experiments. The genes that possess PPRE sequence in their promoter regions, e.g., acyl-CoA oxidase (Tugwood et al.,1992), carnitine palmitoyl transferase I (Brandt et al., 1998), carnitine palmitoyl transferase II (Barrero et al., 2003) and fatty acid desaturase 2 (Tang et al., 2003) were found to be up-regulated both in vivo and in vitro. An exception was that malic enzyme (Castelein et al., 1994), whose promoter region contains PPRE, was induced in vivo but not in vitro. On the other hand, there were many genes whose promoter regions had no
PPRE sequence showing common induction for in vivo and in vitro. For example, CD36, a fatty acid transporter, and CYP4A14, involved in fatty acid hydroxylation, were up-regulated both in vivo and in vitro, but there has been no report that their promoter regions contain functional PPRE. Apart from their mechanism, the genes that show common changes in vivo and in vitro (as listed by the present study) are considered to be useful to assess pharmacological and toxicological effects in vivo from in vitro experiments. This will be discussed later.

There were also data suggesting the limitations of in vitro experiments. Among the genes modulated by administration of fibrates in vivo, those related to the functions of proliferation, apoptosis, immune response, transcription activation and repression, transporter, cell adhesion, blood coagulation and regulation of blood pressure, did not show any changes in vitro. It is well known that peroxisome proliferators are nongenotoxic carcinogens for rodents and their most convincing mechanism is presently considered to be the activation of proliferation in addition to attenuation of apoptosis (Michalik et al., 2004; Boitier et al., 2003). In the present study, many of the genes related to proliferation and apoptosis were mobilized by fibrates in vivo but not at all in vitro. There have been many reports describing the fact that stimulation of proliferation by peroxisome proliferators requires Kupffer cell or TNF $\alpha$ produced by the cell. Rose et al. (1997) 


\section{K. TAMURA et al.}

reported that acceleration of proliferation in rat hepatocytes by WY-14643 was attenuated by the reduction of TNF $\alpha$ via inactivation of Kupffer cells. It was also reported that WY-14643 failed to cause cell proliferation in hepatic parenchymal cells cultured under the condition where non-parenchymal cells had been elim- inated, and that its proliferative effect was recovered when Kupffer cells were added to the culture (Parzefall et al., 2001). As for the attenuation of apoptosis, it was reported that a high concentration of $\mathrm{TNF} \alpha$ inhibited spontaneous TGF $\beta 1$-induced apoptosis in primary cultured hepatocytes (Rolfe et al., 1997). These reports

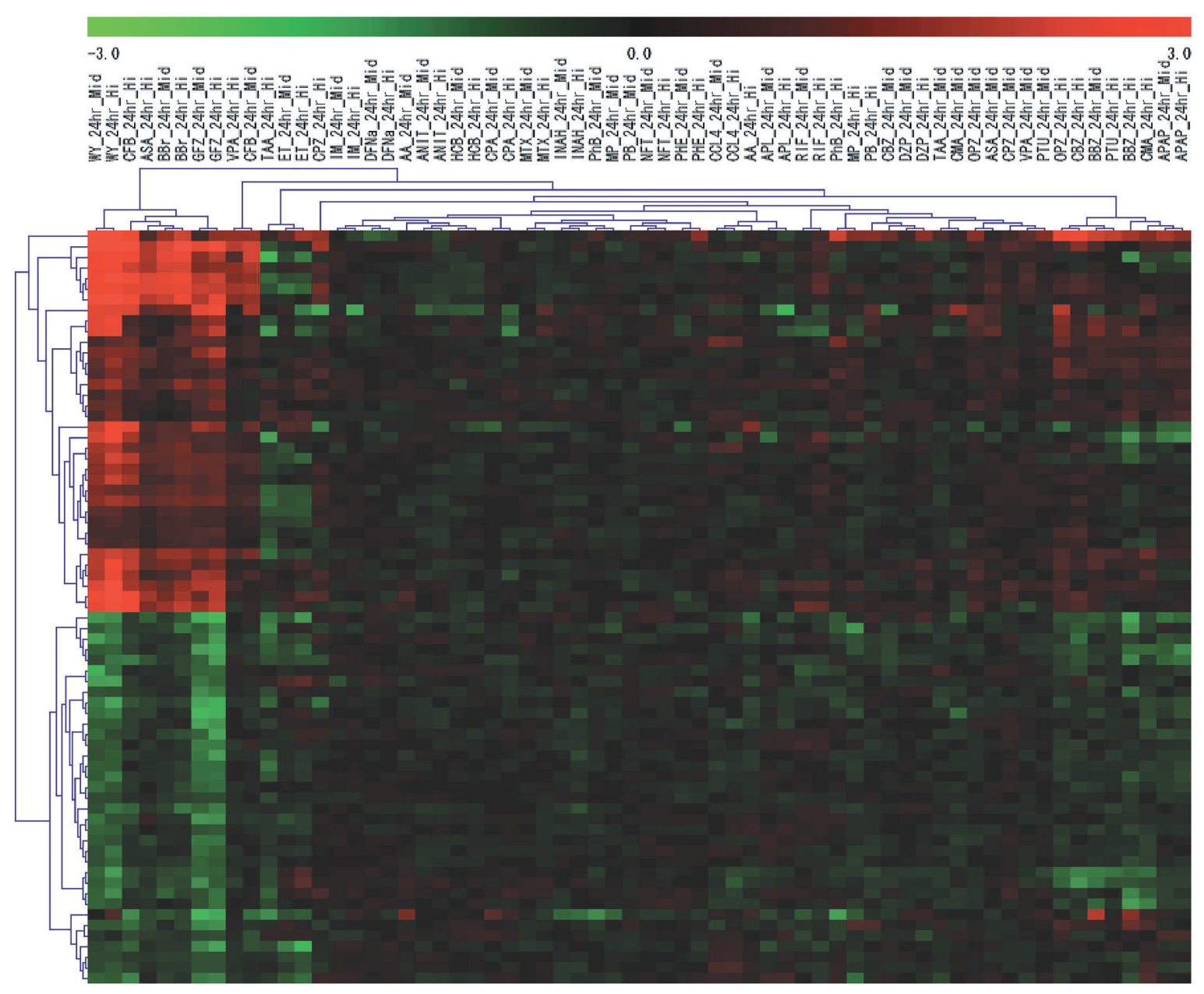

Fig. 3. A heat map view of the gene expression profile for the 32 compounds in vivo. Hierarchical clustering analysis of the compounds (middle and high dose, $24 \mathrm{hr}$ after a single dose) was conducted using the genes that were increased (1398296_at, 1398249_at, 1390851_at, 1389551_at, 1389253_at, 1388924_at, 1388891_at, 1388756_at, 1388223_at, 1387977_at, 1387783_a_at, 1387740_at, 1387636_a_at, 1387183_at, 1387022_at, 1386927_at, 1386885_at, 1386880_at, 1379361_at, 1375845_at, 1374475_at, 1373784_at, 1373564_at, 1372134_at, 1371976_at, 1371379_at, 1370870_at, 1370818_at, 1370397_at, 1370067_at, 1368934_at, 1368283_at, 1367937_at, 1367777_at, 1367694_at, 1367659_s_at) or decreased (1398362_at, 1391485_at, 1390172_at, 1390165_at, 1390115_at, 1389218_at, 1388742_at, 1388459_at, 1387913_at, 1382944_at, 1377375_at, 1376746_at, 1376709_at, 1376593_at, 1376140_at, 1375205_at, 1374499_at, 1374320_at, 1374266_at, 1373797_at, 1372308_at, 1371368_at, 1371202_a_at, 1370043_at, 1369973_at, 1369868_at, 1368698_at, 1368642_at, 1368497_at, 1368428_at, 1368304_at, 1368036_at, 1367905_at, 1367602_at, 1367601_at) 24 hr after a single dose (complete linkage method, Euclidean distance). A cluster consisting of 3 fibrates (CFB, WY, GFZ), benzbromarone $(\mathrm{BBr})$ and aspirin (ASA) was identified on the left side. 
PPAR on rat liver gene expression in vivo and in vitro.

suggest that a Kupffer cell secreting TNF $\alpha$, IL-1, IL-2 and IL-6 (Decker, 1990) plays an important role in hepatocyte proliferation stimulated by peroxisome proliferators. Our present results that the expression changes of genes related to proliferation or apoptosis were rarely observed for the in vitro system could be due to the fact that the numbers of non-parenchymal cells (including Kupffer cells) in the culture were much less than that for in vivo liver. Our present results also support the aforementioned concept that the Kupffer cell (or its production of TNF $\alpha$ ) is essential for the increase of proliferation and attenuation of apoptosis caused by peroxisome proliferators.

Many genes related to cellular morphogenesis, including extracellular matrix (ECM), were down-regulated exclusively in vivo. Ogata et al. (2002, 2004) reported that the increase in mRNA of collagen type I and type III in pressure-overloaded rat heart was reduced by the administration of fenofibrate and that the proliferation of cardiac fibroblast induced by endothelin-1 was inhibited by fenofibrate. It was also reported that ETYA, a PPAR $\alpha$ agonist, reduced the mRNA contents of elastin, tropoelastin and $\alpha$-smooth muscle actin in neonatal rat lung fibroblast (McGowan

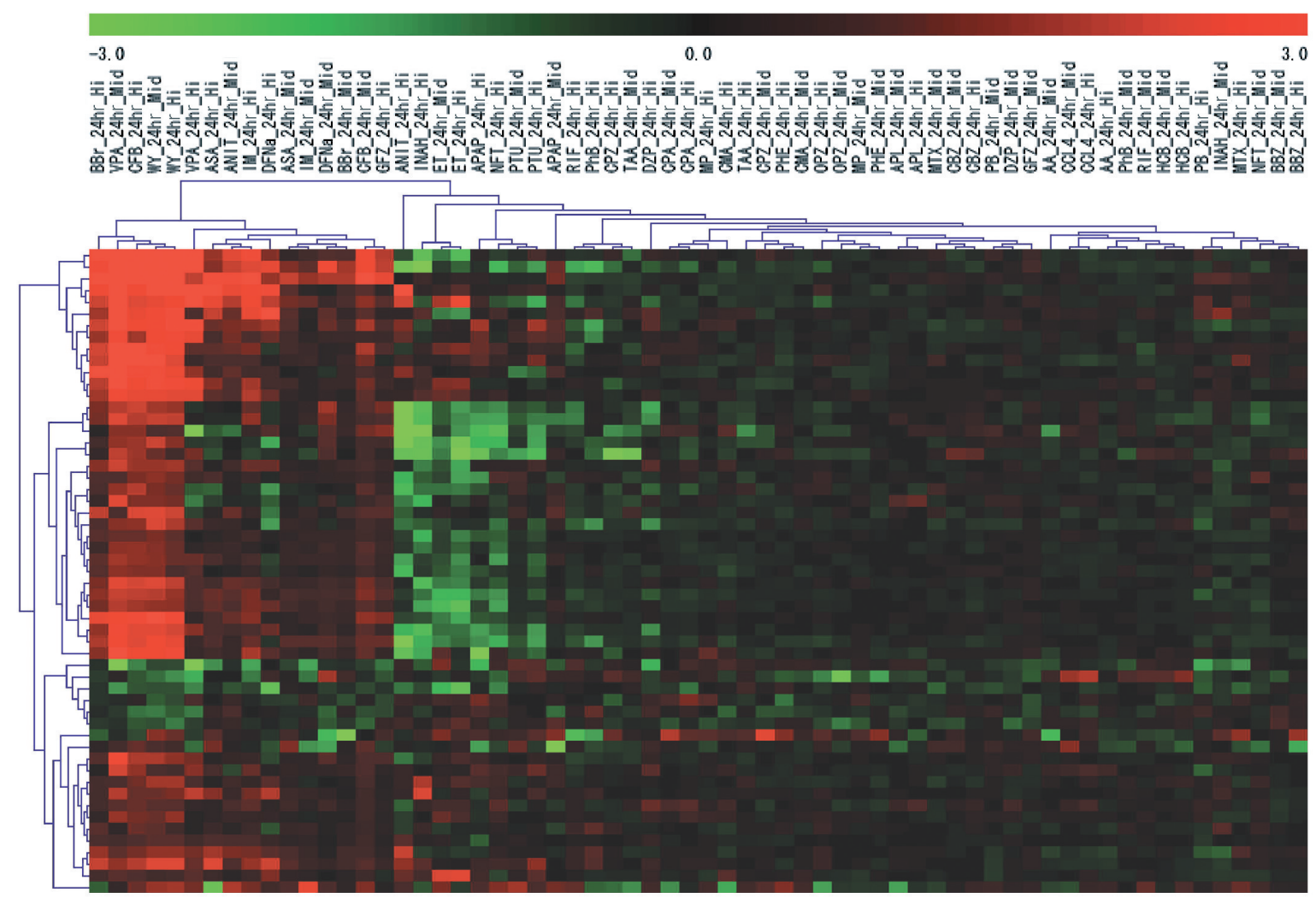

Fig. 4. A heat map view of the gene expression profile for the 32 compounds in vitro. Hierarchical clustering analysis of the compounds (middle \& high concentrations, $24 \mathrm{hr}$ of exposure) was conducted using the genes that were increased (1398310_at, 1394194_x_at, 1390383_at, 1390370_at, 1389253_at, 1388924_at, 1388756_at, 1388644_at, 1388211_s_at, 1388108_at, 1387783_a_at, 1387740_at, 1386946_at, 1386927_at, 1386901_at, 1386885_at, 1386880_at, 1383205_at, 1379361_at, 1377037_at, 1376076_at, 1374556_at, 1374478_at, 1374265_at, 1370818_at, 1370436_at, 1370397_at, 1370355_at, 1370313_at, 1370310_at, 1370237_at, 1369150_at, 1369111_at, 1368934_at, 1368797_at, 1368669_at, 1368435_at, 1368283_at, 1368150_at, 1368034_at, 1368021_at, 1367950_at, 1367897_at, 1367836_at, 1367777_at, 1367742_at, 1367689_a_at, 1367672_at, 1367659_s_at) or decreased (1387246_at, 1375791_at, 1373261_at, 1369093_at, 1368798_at, 1368342_at) in 24 hr of exposure (complete linkage method, Euclidean distance). A cluster consisting of 3 fibrates (CFB,WY, GFZ), 3 NSAIDs (asprin [ASA], indomethacin [IM] and diclofenac sodium [DFNa]), valproic acid (VPA) and benzbromarone $(\mathrm{BBr})$ was identified on the left side. Although the middle dose of ANIT belonged to the same cluster, its high dose did not. 


\section{in vivo}

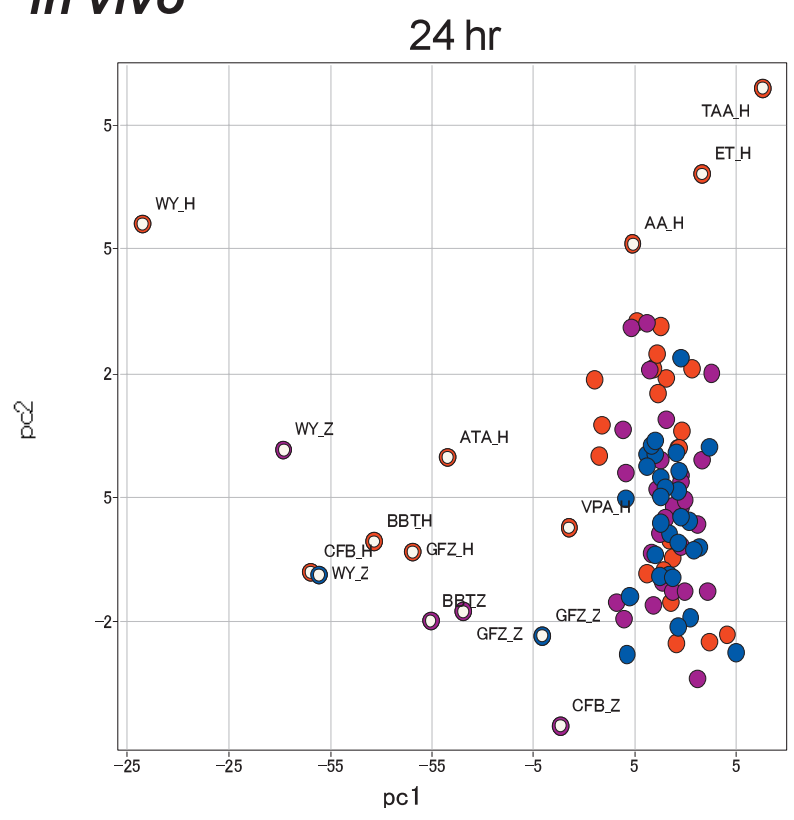

\section{in vitro}

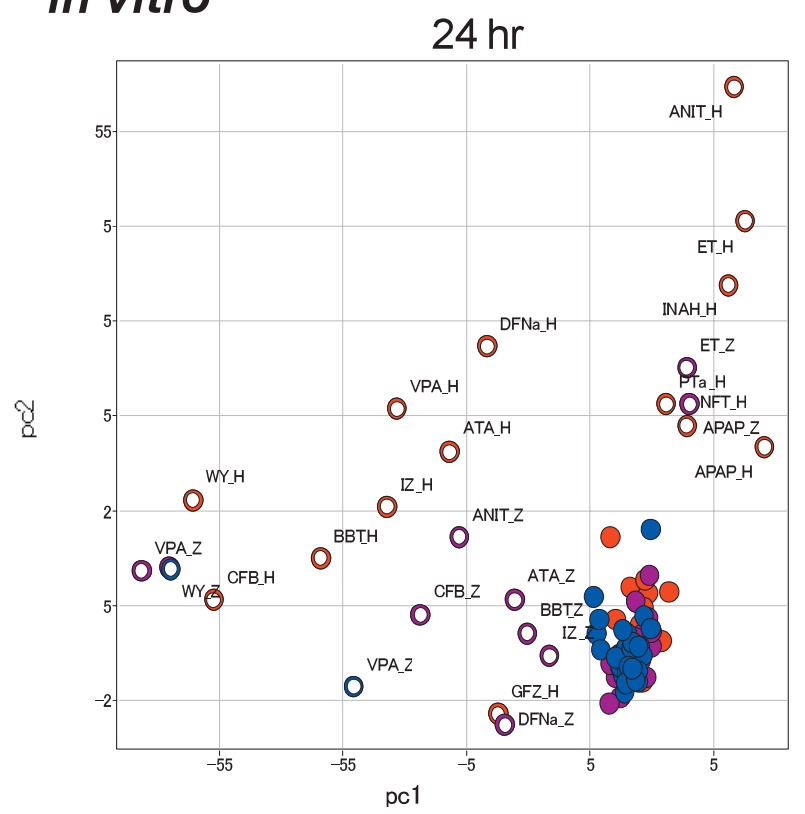

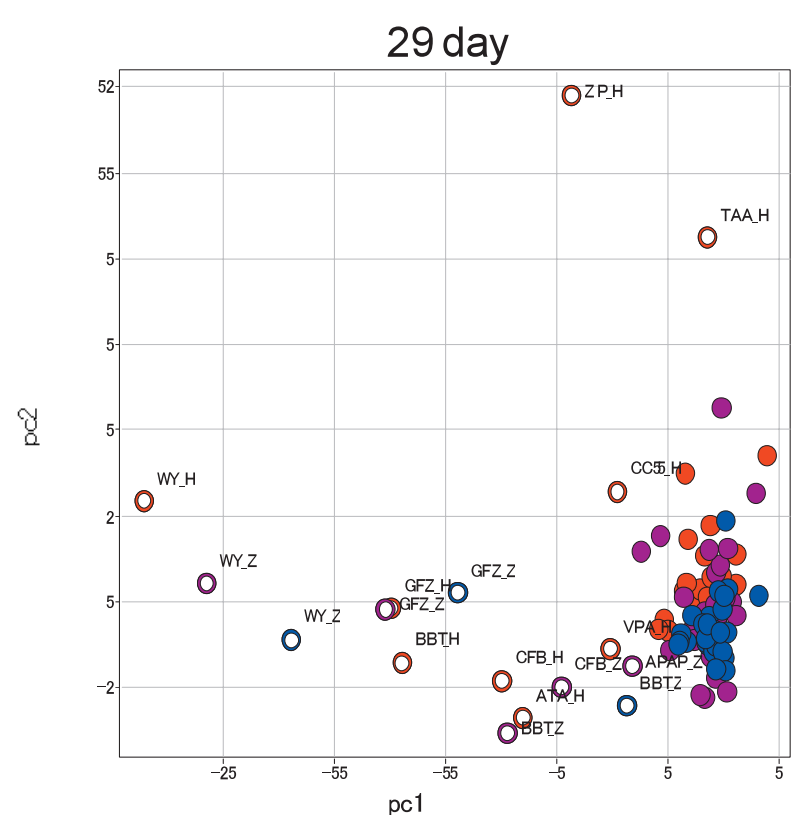

Contribution of principal component in each experimental method

\begin{tabular}{llrrr} 
& & PC 1 & PC2 & PC3 \\
\hline in vivo & $24 \mathrm{hr}$ & 59.92559 & 7.75393 & 5.10374 \\
& $29 \mathrm{day}$ & 61.68536 & 9.71071 & 6.16794 \\
in vitro & $24 \mathrm{hr}$ & 59.38938 & 12.54682 & 4.78532 \\
\hline
\end{tabular}

Colors showing dose levels of compound

- Low

- Middle

- High

Fig. 5. Two-dimensional visualization of principal component analysis of the 32 compounds in vivo and in vitro using the commonly up-regulated 41 genes between in vivo and in vitro. The upper two panels show the in vivo studies and the lower left panel shows the in vitro study. Within each plot, the highest contributing factor to the overall variability is shown on the $\mathrm{x}$-axis as the first component (PC1). The y-axis shows the second highest component (PC2). These plots show the principal separation of samples due to putative PPAR $\alpha$ activity toward the negative direction on the $\mathrm{x}$-axis, PC1. The contributions (\%) of principal components for each experiment are summarized in the table on the lower right. 
PPAR on rat liver gene expression in vivo and in vitro.

\section{in vivo}

Fig. 6. Plotting of the first principal component (PC1) from the 32 compounds examined in vivo and in vitro. The left two panels show the in vivo studies, i.e., $24 \mathrm{hr}$ after single dose and $24 \mathrm{hr}$ after the last dose of the 28-day repeated dose, and the right panel shows the in vitro study, $24 \mathrm{hr}$ exposure. The $\mathrm{x}$-axis for each shows the negative value of PC1, as in Fig. 5, and the y-axis shows the compounds aligned alphabetically. The abbreviations of the compounds are found in Table 1. Note that the three fibrates (CFB, GFZ, WY), aspirin (ASA), and benzbromarone (BBr) show high values in this parameter for in vivo experiments and that diclofenac sodium (DFNa) and indomethacin (IM) show high values in addition to the drugs above. 
et al., 1997). It appears that peroxisome proliferators also act on non-parenchymal cells other than Kupffer cells, and that they reduce the production of ECM in fibroblasts. Stellate cell, a hepatic non-parenchymal cell, possesses both of the characteristics of lipocyte and fibroblast, and its ability to produce ECM was found to be increased in liver fibrosis (Tanaka et al., 1991). It is possible that production of ECM in stellate cells could be stimulated by peroxisome proliferators. Based on these ideas, it would be reasonable to conclude that the reduction of expression of genes related to ECM and cytoskeletons by peroxisome proliferators observed in vivo were not reproduced in the in vitro system, considering that these changes were a reflection of those occurring in non-parenchymal cells in liver. In the present study, relative liver weight was increased by a factor of two in peroxisome proliferators. The expression changes in genes classified to cell adhesion and cellular morphogenesis should have been associated with this obvious hypertrophy of the liver.

In the present study, down-regulation of genes classified to the immune response and coagulation was also in vivo-specific. PPAR $\alpha$ is known to function as an inhibitory factor for inflammation, and PPAR $\alpha$ agonists were reported to inhibit the expression of mRNA of fibrinogen, an acute phase protein (Kockx et al., 1999; Corton et al., 1998), and induction of fibrinogen gene by IL-6 (Gervois et al., 2001). Moreover, it was also reported that WY-14643 inhibits induction of IL-6 and cyclooxygenase- 2 by IL-1 in human aortic smooth muscle cells through inhibition of the translocation of $\mathrm{NF}-\kappa \mathrm{B}$ from the cytosol to the nucleus. It is thus expected that inhibition of the inflammatory response by PPAR $\alpha$ agonists not only affects the hepatic parenchymal cell (producing acute phase proteins) but also affects the mechanism relating to non-parenchymal cells (including Kupffer cell) that releases inflammatory cytokines. It would be reasonable to conclude that the reason down-regulation of genes classified to the immune response and coagulation was observed in vivo but not in vitro was again due to the involvement of non-parenchymal cells. However, it might be due simply to the fact that the basal level of the mRNAs of these genes was down-regulated during our culture condition, since there was a report that PPAR $\alpha$ agonist could inhibit the expression of fibrinogen mRNA by IL-6, using human hepatocyte culture (Gervois et al., 2001).

As discussed above, the profiling of in vivo data represents gene expression in multiple cellular populations, whereas the profiling of in vitro data is focused on gene expression of hepatic parenchymal cells. The advantage of the in vitro system is that the direct effects of chemicals on hepatic parenchymal cells can be assessed, and in certain cases, the sensitivity and specificity of the test can be improved by eliminating noise due to gene expression of non-parenchymal cells. On the other hand, the in vitro system has an apparent disadvantage when indirect toxicity to parenchymal cells via non-parenchymal cells is involved or direct toxicity to non-parenchymal cells is involved.

In hierarchical clustering analysis of the in vivo data stored in our database, benzbromarone and aspirin were classified into the same cluster of the three peroxisome proliferators. It has been long known that benzbromarone is a PPAR $\alpha$ ligand (Bichet et al., 1990). As for aspirin, some NSAIDs including indomethacin, ibuprofen and fenoprofen, were reported to activate PPAR $\alpha$ (Lehmann et al., 1997), suggesting that aspirin belongs to PPAR $\alpha$ agonists as well. In the hierarchical clustering of the in vitro data, two NSAIDs (indomethacin and diclofenac) and valproic acid were additionally located to the same cluster that included the three fibrates, and benzbromarone and aspirin. It has been reported that valproic acid induced the increase of liver weight and the activation of $\beta$-oxidation in rodents, suggesting that the drug has some PPAR $\alpha$ agonist-like activity (Horie and Suga, 1985). Although the middle dose of ANIT belonged to the same cluster, its high dose showed a quite different profile. There is no report suggesting a relationship between ANIT and PPAR $\alpha$ so far. One possibility is that ANIT is a potential PPAR $\alpha$ agonist, and inconsistent results at high concentrations showed that cytotoxicity overwhelmed the inducing effects. At the middle dose of ANIT, various genes related to lipid metabolism (including $\beta$-oxidation), e.g., Acaa1, Acaa2, Cpt1a, Cpt1b, Pdk4, Ehhadh, Hmgcs2, Mte1, Cyp4a14, Cyp4b1, Cyp8b1, and Angpt14 were up-regulated more than twice of control in vitro. It would be interesting to examine the direct effect of ANIT on PPAR $\alpha$. It should be considered that any expression changes in $\beta$-oxidation-related genes do not necessarily indicate the direct involvement of PPAR $\alpha$.

The reason why the in vitro system was more sensitive than that of in vivo for detecting PPAR $\alpha$ agonistlike activity is the high concentration of the drugs in vitro. In the standard protocol in our project, the maximal dose of the drugs in vivo is set to the level which the animals can tolerate for 28 days of repeated administration, while that for in vitro is independently determined according to the direct cytotoxicity of the cul- 
PPAR on rat liver gene expression in vivo and in vitro.

tured hepatocytes. Therefore, in the case of chemicals causing severe toxicity to organs other than the liver, the practical concentration around the hepatocyte becomes much lower in vivo than in vitro. Since the main lethal cause in the case of NSAIDs is intestinal perforation, the doses employed were relatively low compared with that needed to elicit PPAR $\alpha$ activation in vivo, and actually, a reduction of plasma lipid was barely observed. The PPAR $\alpha$ activity of aspirin could possibly have been detected because its ulcerogenicity to intestine is much lower than that of the other NSAIDs.

One of the aims of the present project is the prediction of in vivo effects from in vitro experiments that have the advantages of saving chemicals, cost, and time. In the case of PPAR $\alpha$ agonists, we could not find any common genes in down-regulated ones between in vivo and in vitro. On the other hand, 41 genes up-regulated in vitro were also up-regulated in vivo. We considered these as useful markers to predict PPAR $\alpha$ activity in vivo from in vitro, and applied them to PCA. As shown in Fig. 5, PC1 appeared to have a PPAR $\alpha$ agonist-like attribute, and 32 chemicals were aligned by this parameter in Fig. 6 . This presentation conveniently identifies potential PPAR $\alpha$ agonists both in vivo and in vitro. We are now incorporating this computing module into our toxicity prediction system and it will be useful in identifying other properties when appropriate marker genes are extracted.

In conclusion, our database efficiently works to classify a certain category of drugs (PPAR $\alpha$ agonist in the present case) based on gene expression profiling. For these data, the gene expression profile in vitro is useful and sensitive to the direct toxicity of the chemicals in hepatic parenchymal cells, whereas indirect toxicities mediated by other cells or secondary toxicity due to pathophysiological changes such as blood pressure or inflammation in other organs might be overlooked. In order to predict in vivo effects from the in vitro system, it is important to identify genes commonly mobilized in vivo and in vitro. The scoring system (using the principal component that largely contributes the target effect) in the present study appeared to be quite useful and convenient to identify compounds with target activity among the ones stored in our database.

\section{ACKNOWLEDGMENT}

This study was supported in part by a grant from the Ministry of Health, Labor and Welfare (H14-Tox- ico-001).

\section{REFERENCES}

Barrero, M.J., Camarero, N., Marrero, P.F. and Haro, D. (2003): Control of human carnitine palmitoyltransferase II gene transcription by peroxisome proliferator-activated receptor through a partially conserved peroxisome proliferatorresponsive element. Biochem. J., 369, 721-729.

Bichet, N., Cahard, D., Fabre, G., Remandet, B., Gouy, D. and Cano, J.P. (1990): Toxicological studies on a benzofuran derivative. III. Comparison of peroxisome proliferation in rat and human hepatocytes in primary culture. Toxicol. Appl. Pharmacol., 106, 509-517.

Boitier, E., Gautier, J.C. and Roberts, R. (2003): Advances in understanding the regulation of apoptosis and mitosis by peroxisome-proliferator activated receptors in pre-clinical models: Relevance for human health and disease. Comp. Hepatol., 2, 3.

Brandt, J.M., Djouadi, F. and Kelly, D.P. (1998): Fatty acids activate transcription of the muscle carnitine palmitoyltransferase I gene in cardiac myocytes via the peroxisome proliferator-activated receptor alpha. J. Biol. Chem., 273, 23786-23792.

Castelein, H., Gulick, T., Declercq, P.E., Mannaerts, G.P., Moore, D.D. and Baes, M.I. (1994): The peroxisome proliferator activated receptor regulates malic enzyme gene expression. J. Biol. Chem., 269, 26754-26758.

Corton, J.C., Fan, L.Q., Brown, S., Anderson, S.P., Bocos, C., Cattley, R.C., Mode, A. and Gustafsson, J.A. (1998): Down-regulation of cytochrome P450 2C family members and positive acute-phase response gene expression by peroxisome proliferator chemicals. Mol. Pharmacol., 54, 463-473.

Decker, K. (1990): Biologically active products of stimulated liver macrophages (Kupffer cells). Eur. J. Biochem., 192, 245-261.

Gervois, P., Vu-Dac, N., Kleemann, R., Kockx, M., Dubois, G., Laine, B., Kosykh, V., Fruchart, J.C., Kooistra, T. and Staels, B. (2001): Negative regulation of human fibrinogen gene expression by peroxisome proliferator-activated receptor alpha agonists via inhibition of CCAAT box/ enhancer-binding protein beta. J. Biol. Chem., 276, 33471-33477. 
Horie, S. and Suga, T. (1985): Enhancement of peroxisomal beta-oxidation in the liver of rats and mice treated with valproic acid. Biochem. Pharmacol., 34, 1357-1362.

Kockx, M., Gervois, P.P., Poulain, P., Derudas, B., Peters, J.M., Gonzalez, F.J., Princen, H.M., Kooistra, T. and Staels, B. (1999): Fibrates suppress fibrinogen gene expression in rodents via activation of the peroxisome proliferator-activated receptor-alpha. Blood, 93, 2991-2998.

Kramer, J.A., Blomme, E.A., Bunch, R.T., Davila, J.C., Jackson, C.J., Jones, P.F., Kolaja, K.L. and Curtiss, S.W. (2003): Transcription profiling distinguishes dose-dependent effects in the livers of rats treated with clofibrate. Toxicol. Pathol., 31, 417-431.

Lehmann, J.M., Lenhard, J.M., Oliver, B.B., Ringold, G.M. and Kliewer, S.A. (1997): Peroxisome proliferator-activated receptors alpha and gamma are activated by indomethacin and other non-steroidal anti-inflammatory drugs. J. Biol. Chem., 272, 3406-3410.

McGowan, S.E., Jackson, S.K., Doro, M.M. and Olson, P.J. (1997): Peroxisome proliferators alter lipid acquisition and elastin gene expression in neonatal rat lung fibroblasts. Am. J. Physiol., 273, L1249-L1257.

Michalik, L., Desvergne, B. and Wahli, W. (2004): Peroxisome-proliferator-activated receptors and cancers: Complex stories. Nat. Rev. Cancer, 4, 61-70.

Ogata, T., Miyauchi, T., Sakai, S., Irukayama-Tomobe, Y., Goto, K. and Yamaguchi, I. (2002): Stimulation of peroxisome-proliferator-activated receptor alpha (PPAR alpha) attenuates cardiac fibrosis and endothelin-1 production in pressure-overloaded rat hearts. Clin. Sci. (Lond), 103, (Suppl 48), 284S-288S.

Ogata, T., Miyauchi, T., Irukayama-Tomobe, Y., Takanashi, M., Goto, K. and Yamaguchi, I.
(2004): The Peroxisome Proliferator-activated Receptor alpha Activator Fenofibrate Inhibits Endothelin-1-induced Cardiac Fibroblast Proliferation. J. Cardiovasc. Pharmacol., 44, (Suppl 1), S279-S282.

Parzefall, W., Berger, W., Kainzbauer, E., Teufelhofer, O., Schulte-Hermann, R. and Thurman, R.G. (2001): Peroxisome proliferators do not increase DNA synthesis in purified rat hepatocytes. Carcinogenesis, 22, 519-523.

Rolfe, M., James, N.H. and Roberts, R.A. (1997): Tumour necrosis factor alpha (TNF alpha) suppresses apoptosis and induces DNA synthesis in rodent hepatocytes: A mediator of the hepatocarcinogenicity of peroxisome proliferators? Carcinogenesis, 18, 2277-2280.

Rose, M.L., Germolec, D.R., Schoonhoven, R. and Thurman, R.G. (1997): Kupffer cells are causally responsible for the mitogenic effect of peroxisome proliferators. Carcinogenesis, 18 1453-1456.

Tanaka, Y., Nouchi, T., Yamane, M., Irie, T., Miyakawa, H., Sato, C. and Marumo, F. (1991): Phenotypic modulation in lipocytes in experimental liver fibrosis. J. Pathol., 164, 273-278.

Tang, C., Cho, H.P., Nakamura, M.T. and Clarke, S.D. (2003): Regulation of human delta- 6 desaturase gene transcription: Identification of a functional direct repeat-1 element. J. Lipid Res., 44, 686695.

Tugwood, J.D., Issemann, I., Anderson, R.G., Bundell, K.R., McPheat, W.L. and Green, S. (1992): The mouse peroxisome proliferator activated receptor recognizes a response element in the 5' flanking sequence of the rat acyl CoA oxidase gene. EMBO J., 11, 433-439.

Urushidani, T. and Nagao, T. (2005): Toxicogenomics: The Japanese initiative. In Handbook of Toxicogenomics - Strategies and Applications (Borlak, J., ed.), pp. 623-631. Wiley - VCH. 